\title{
Predictors and one-year outcomes of patients with delayed graft function after deceased donor kidney transplantation
}

\author{
Rao Chen ${ }^{1,2}$, Haifeng Wang ${ }^{1,2}$, Lei Song ${ }^{1,2}$, Jianfei Hou ${ }^{1,2}$, Jiawei Peng ${ }^{1,2}$, Helong Dai ${ }^{1,2,3^{*}}$ and Longkai Peng ${ }^{1,2^{*}}$ (D)
}

\begin{abstract}
Background: Delayed graft function (DGF) is closely associated with the use of marginal donated kidneys due to deficits during transplantation and in recipients. We aimed to predict the incidence of DGF and evaluate its effect on graft survival.
\end{abstract}

Methods: This retrospective study on kidney transplantation was conducted from January 1, 2018, to December 31, 2019, at the Second Xiangya Hospital of Central South University. We classified recipients whose operations were performed in different years into training and validation cohorts and used data from the training cohort to analyze predictors of DGF. A nomogram was then constructed to predict the likelihood of DGF based on these predictors.

Results: The incidence rate of DGF was $16.92 \%$. Binary logistic regression analysis showed correlations between the incidence of DGF and cold ischemic time (CIT), warm ischemic time (WIT), terminal serum creatine (Scr)

concentration, duration of pretransplant dialysis, primary cause of donor death, and usage of LifePort. The internal accuracy of the nomogram was $83.12 \%$. One-year graft survival rates were 93.59 and $99.74 \%$, respectively, for the groups with and without DGF $(P<0.05)$.

Conclusion: The nomogram established in this study showed good accuracy in predicting DGF after deceased donor kidney transplantation; additionally, DGF decreased one-year graft survival.

Keywords: Delayed graft function, Predictors, Nomogram, Deceased donation, Graft survival

\section{Background}

Kidney transplantation has been successful and has saved numerous lives since the 1960s. Compared to regular kidney dialysis, kidney transplantation results in better patient quality of life and longer survival [1]. Deceased donation (DD), including donation after brain death (DBD), donation after cardiac death (DCD), and donation after brain death awaiting cardiac death (DBCD), has been promoted in recent years throughout China, allowing an increasing numbers of patients to

\footnotetext{
*Correspondence: helong68888@csu.edu.cn; penglongkai@csu.edu.cn 'Department of Kidney Transplantation, The Second Xiangya Hospital of Central South University, Changsha, Hunan 410011, China

Full list of author information is available at the end of the article
}

recover from uremia. However, DGF is one of the most common postoperative complications $[2,3]$, the incidence of which varies from 5 to $50 \%$ in DD kidney transplantation. There is a scarcity of donated kidneys, and the use of marginal kidneys has dramatically increased the incidence of DGF, which is not only a risk factor for acute rejection but is also associated with poor longterm survival of the graft $[4,5]$. Some centers believe that DGF in transplantation is a specific manifestation of acute tubular necrosis (ATN) during the procedure [6]. In general, renal graft function recovery includes the following types: immediate graft function (IGF), slow graft function (SGF), and DGF.

(c) The Author(s). 2020 Open Access This article is licensed under a Creative Commons Attribution 4.0 International License, which permits use, sharing, adaptation, distribution and reproduction in any medium or format, as long as you give appropriate credit to the original author(s) and the source, provide a link to the Creative Commons licence, and indicate if changes were made. The images or other third party material in this article are included in the article's Creative Commons licence, unless indicated otherwise in a credit line to the material. If material is not included in the article's Creative Commons licence and your intended use is not permitted by statutory regulation or exceeds the permitted use, you will need to obtain permission directly from the copyright holder. To view a copy of this licence, visit http://creativecommons.org/licenses/by/4.0/. The Creative Commons Public Domain Dedication waiver (http://creativecommons.org/publicdomain/zero/1.0/) applies to the data made available in this article, unless otherwise stated in a credit line to the data. 
Various potential factors affect the rate of DGF, including the induction strategy, donor criteria, and surgical process, among others. Our center utilizes expanded criteria donor (ECD) kidneys to address the shortage, which has also been recognized by the Organ Procurement and Transplantation Network (OPTN) in recent years [7]. Kidney transplantations from pediatric donors were shown to be safe in a recent study [8]. Our center has also adopted partial graft from young children $(\leq 12$ years) [9]; despite the difficulty of surgery, the youngest donor in this study was only 5 months old. Considering the contradiction between marginal kidneys and DGF, this retrospective study was conducted based on the medical records of our center to investigate pretransplant risk factors for DGF. This study also established a visual scoring system (nomogram) model for predicting clinical outcomes regarding the incidence of DGF. Finally, we compared graft survival between DGF and non-DGF groups.

\section{Methods \\ Patients}

Data for consecutive patients who had undergone kidney transplantation surgery were collected at the Second Xiangya Hospital of Central South University. The study was approved by the Ethics Committee of the Second Xiangya Hospital of Central South University, which waived the requirement for informed consent due to the retrospective design. The inclusion criteria were (1) grafts obtained from DD, (2) surgery performed as single-kidney transplantation, (3) and patients with complete data. Patients with a history of kidney transplantation or who had received double-kidney transplantations or grafts from living donors were excluded. The term ECD was used to classify subsets of all DDs over 60 years and DDs aged $50-59$ years with at least two of the following characteristics: history of hypertension, serum creatinine (Scr) concentration above $1.5 \mathrm{mg} / \mathrm{dL}$, and DCD [10]. Among marginal kidneys, if possible, we used LifePort Kidney Transporters for hypothermic machine perfusion (HPM) to potentially minimize preservation injury. DGF was defined as the requirement for dialysis within the first week after transplantation [11, 12]. We further classified patients into those who did or did not experience DGF.

Eligible patients who underwent surgery between January 1 and December 31, 2018, were included in the training cohort for the development of the nomogram; those who underwent surgery between January 1 and December 31,2019 , were included in the validation cohort.

\section{LifePort}

Hemodynamic instability will destroy the utility of organs if the kidney has a long WIT or hypotension, which may cause blood clots, affecting the appearance and texture of the kidney. When we found a kidney that was reddish in color or slightly tough in texture, we used LifePort to evaluate and improve its quality before making a decision. A flow of $>80 \mathrm{~mL} / \mathrm{min}$ was the screening criterion of transplantation qualification [13]. We chose $30 \mathrm{mmHg}$ as the initial pressure and $2 \mathrm{~h}$ as the average perfusion time If the average terminal flow was less than $80 \mathrm{~mL} / \mathrm{min}$, the kidney was discarded. Other kidneys with good appearance and texture were not subjected to HMP (LifePort), we classify LifePort as "No" in Table 2.

\section{Immunity induction therapy}

Antithymocyte globulin (ATG) or interleukin 2 (IL-2) receptor antibody blockers with steroids were used as induction therapy according to the surgeons' experience. As some surgeons only administered steroids and drugs for cases with a significant risk of infection, we classify immunity induction as "Yes" or "No" in Table 2.

\section{Relevant variables}

DGF-related factors included donor and recipient factors. We collected donor data, including age, sex, height, weight, BMI, blood type, CIT, WIT, primary cause of death, terminal urine volume before organ harvest, terminal Scr concentration before organ harvest, intensive care unit (ICU) duration, hypotension history, cardiac arrest time, donation type, history of hypertension and diabetes, history of cardiopulmonary resuscitation (CPR), history of hepatitis $\mathrm{C}$ virus (HCV) and usage of LifePort. The kidney donor profile index (KDPI), as an influencing factor of graft survival and DGF in some centers [14-16], was also incorporated into our study.

Recipient indicators included sex, age, height, weight, BMI, preoperative Scr concentration, number of human leukocyte antigen (HLA) mismatches, preoperative plasma renin activity (PRA) level, dialysis type, pretransplant dialysis duration, surgery duration, and immunity induction history.

\section{Statistics}

Statistical analyses were conducted using IBM SPSS Statistics for Windows, version 23.0. For univariate analysis, continuous variables were compared using unpaired, two-tailed t-tests; categorical variables were compared by $\chi^{2}$ or Fisher exact tests when data were sparse. Binary logistic regression was performed to assess the impact of significant DGF-related factors in univariate analysis. $P$ values $<0.05$ were considered statistically significant. $\mathrm{R}$ software version 4.0 were used to graphically depict the impact of significant risk factors identified in the binary logistic regression and to develop the nomogram. We used the parameters of the odds ratios and $\beta$ of the predictors to assess the likelihood of DGF. 
The internal predictive accuracy of the model was evaluated in the training cohort using the area under the receiver operating characteristic curve (AUC) derived from 10-fold cross-validation by the least absolute shrinkage and selection operator (LASSO). The validation cohort was used to perform external validation by logistic analysis and calibration curves were plotted to examine the calibration of the nomogram, accompanied by Hosmer-Lemeshow tests. One-year graft survival curves were generated using the Kaplan-Meier method and compared using log-rank tests.

\section{Results}

\section{Patient screening}

During the study period, 858 consecutive patients underwent kidney transplantation. Of these, 721 patients who met the inclusion criteria were enrolled, with 461 and 260 patients assigned to the training and validation cohorts, respectively (Figure S1 in the Supplement). The training cohort included 78 cases with DGF and 383 cases without DGF; the validation cohort included 23 cases with DGF and 237 cases without DGF.

\section{Univariate analysis of the training cohort}

With regard to the training cohort data, the proportion of ECD was $20.82 \%$, and the incidence of DGF was 16.92\%; ECD showed no statistical significance with the occurrence of $\operatorname{DGF}(P>0.05)$. The recipients tended to be younger with just five people older than 60 years old; the median age was 37 years old. The percentages of young child donors ( $\leq 12$ years) and aged donor $(\geq 60$ years) were 13.88 and $17.15 \%$, respectively. The remaining significant $(P<0.05)$ variables were fitted to a binary logistic regression model. Continuous variables (Table 1) are presented as means and standard deviations (SDs) and categorical data (Table 2) as proportions and percentages.

\section{Binary logistic regression analysis}

Risk factors with statistical significance in the univariate analysis were sequentially examined using binary logistic regression analysis. However, only six factors correlated significantly with DGF occurrence, including CIT, WIT, donor terminal Scr, usage of LifePort, primary cause of death, and recipient duration of pretransplant dialysis (Table 3).

\section{DGF risk nomogram}

To visualize the results of binary logistic regression, we used all data for the six significant variables to develop a nomogram model, as shown in Fig. 1. One hundred points were assigned to the most effective factor (WIT) in the nomogram, followed by donor terminal Scr (41 points) and primary cause of death (39 points). Usage of
Table 1 Characteristics of each continuous variable

\begin{tabular}{ll}
\hline Variables & Mean \pm SD \\
\hline Donor demographics & $40.91 \pm 19.77$ \\
Age (years) & \\
Donor clinical characteristics & $57 \pm 34$ \\
KDPI (\%) & $59.35 \pm 19.80$ \\
Weight (Kg) & $22.8 \pm 4.29$ \\
BMI (Kg/ ${ }^{2}$ ) & $12.35 \pm 3.86$ \\
CIT (hours) & $1.94 \pm 2.08$ \\
WIT (minutes) & $0.94 \pm 0.56$ \\
Terminal Scr (mg/dL) & $3.25 \pm 12.26$ \\
Cardiac arrest time (minutes) & $173.43 \pm 191.23$ \\
Terminal urine volume (mL/h) & $7.26 \pm 13.6$ \\
Duration of ICU & \\
Recipient demographics & $37.83 \pm 10.50$ \\
Age (years) & \\
Recipient clinical characteristics & $59.72 \pm 12.44$ \\
Weight (Kg) & $22.02 \pm 3.66$ \\
BMI (Kg/m ${ }^{2}$ ) & $23.02 \pm 25.22$ \\
Pretransplant dialysis duration (months) & $11.64 \pm 3.95$ \\
Pretransplant Scr (mg/dL) & $4.16 \pm 1.38$ \\
HLA mismatches & \\
\hline
\end{tabular}

LifePort had the least effect (25 points); CIT was assigned 26 points. Among recipient factors, pretransplant dialysis duration was assigned 29 points. A total score of 89 corresponded to a DGF incidence of $50 \%$.

\section{Model validation}

The nomogram model was internally validated using a cross-validation method through a LASSO binary logistic regression model (Fig. 2). The LASSO model used 10-fold cross-validation via minimum criteria. The AUC was plotted versus log (lambda); the AUC value of 83.12\% indicated that the model was accurate.

External validation was performed with the validation cohort using the logistic regression formula from the training cohort. The statistic $(P=0.636)$ from the Hosmer-Lemeshow test showed good calibration between predicted and observed DGF (Fig. 3). The relatively corrected $\mathrm{C}$-index derived from bootstrapping validation (1000 bootstrap resamples) for the estimation of DGF risk was 0.846 (95\% confidence interval $[\mathrm{CI}], 0.765$ to 0.926).

\section{One-year graft survival follow-up}

Patients from the training cohort were observed every 2 weeks during the first postoperative year. We found that 5 DGF and 1 non-DGF patients experienced graft loss. The 1-year graft survival rates were 93.59 and $99.74 \%$, 
Table 2 Characteristics of each categorical variable

Variables

Donor demographics

Gender, n (\%)

Male

Female

Age, n (\%)

Young children ( $\leq 12$ years)

Adolescents and adults (13-59 years)

The aged ( $\geq 60$ years)

Donor clinical characteristics

Donor type, n (\%)

DBD

DCD

$D B C D$

History of hypertension, n (\%)

Yes

No

Unknown

History of diabetes, n (\%)

Yes

No

Unknown

History of CPR, n (\%)

Yes

No

Primary cause of death, $\mathrm{n}(\%)$

Head trauma

Stroke

Other

History of hypotension, n (\%)

Yes

No

History of HCV, n (\%)

Yes

No

LifePort, n (\%)

Yes

No

Recipient demographics

Gender, n (\%)

Male

Female

Recipient clinical characteristics

Primary disease for renal failure, $\mathrm{n}(\%)$

Diabetes
$59(75.64)$

With DGF $(n=78)$

Without DGF $(n=383)$

59 (75.64)

$262(68.41)$

$19(24.36)$

$121(31.59)$

$10(12.82)$

$12(15.38)$

56 (71.79)

262 (68.41)

67 (17.49)

56 (71.79)

318 (83.03)

21 (26.92)

54 (14.10)

$1(1.28)$

$1(0.26)$

28 (35.90)

123 (32.11)

48 (61.54)

240 (62.66)

2 (2.56)

20 (5.22)

9 (11.54)

38 (9.92)

55 (70.51)

315 (82.25)

14 (17.95)

30 (7.83)

20 (25.64)

59 (15.40)

$58(74.36)$

$324(84.60)$

$2(2.57)$

158 (41.25)

58 (74.36)

161 (42.03)

18 (23.08)

64 (16.71)

54 (69.23)

214 (55.87)

24 (30.77)

169 (44.13)

$2(2.56)$

4 (1.04)

76 (97.44)

379 (98.96)

5 (6.41)

$4(1.04)$

73 (93.59)

379 (98.96)

19 (24.36)

262 (68.41)

121 (31.59) 
Table 2 Characteristics of each categorical variable (Continued)

\begin{tabular}{lll}
\hline Variables & With DGF $(\boldsymbol{n}=\mathbf{7 8})$ & Without DGF $(\boldsymbol{n}=\mathbf{3 8 3})$ \\
\hline Hypertension & $13(16.67)$ & $47(12.27)$ \\
Purpura nephritis & $0(0)$ & $3(0.78)$ \\
Urologic obstruction & $1(1.28)$ & $1(0.26)$ \\
Polycystic kidney & $4(5.13)$ & $6(1.57)$ \\
Vasculitis & $0(0)$ & $9(2.35)$ \\
Other & $58(74.36)$ & $313(81.72)$ \\
PRA level, n (\%) & & $25(6.53)$ \\
Positive & $3(3.85)$ & $358(93.47)$ \\
Negative & $75(96.15)$ & $312(81.46)$ \\
Immunity Induction, n (\%) & $63(80.77)$ & $71(18.54)$ \\
Yes & $15(19.23)$ & \\
No & & \\
\hline
\end{tabular}

Table $\mathbf{3}$ The results of binary logistic regression analysis

\begin{tabular}{|c|c|c|}
\hline Variables & $\beta$ & OR(95\%Cl) \\
\hline \multicolumn{3}{|l|}{ Donor factors } \\
\hline CIT (hours) & 0.075 & $1.078(1.001-1.161)$ \\
\hline WIT (minutes) & 0.086 & $1.303(1.101-1.045)$ \\
\hline Terminal Scr (mg/dL) & 0.641 & $1.899(1.206-2.989)$ \\
\hline Cardiac arrest time (minutes) & 0.015 & $1.015(0.986-1.145)$ \\
\hline \multicolumn{3}{|l|}{ Donation type } \\
\hline DBD & -0.527 & $0.591(0.026-13.651)$ \\
\hline DBCD & -0.495 & $0.610(0.258-1.141)$ \\
\hline \multicolumn{3}{|l|}{ CPR history } \\
\hline No & 0.048 & $1.049(0.417-2.640)$ \\
\hline \multicolumn{3}{|l|}{ History of diabetes } \\
\hline No & -0.461 & $0.631(0.242-1.706)$ \\
\hline Unknown & 0.285 & $1.330(0.403-4.384)$ \\
\hline \multicolumn{3}{|l|}{ Primary cause of death } \\
\hline Head trauma & -2.891 & $0.056(0.012-0.257)$ \\
\hline Stroke & 0.105 & $1.375(0.626-3.019)$ \\
\hline \multicolumn{3}{|l|}{ History of hypotension } \\
\hline No & -0.511 & $0.600(0.313-1.149)$ \\
\hline \multicolumn{3}{|l|}{ LifePort } \\
\hline No & -2.130 & $0.119(0.021-0.666)$ \\
\hline \multicolumn{3}{|l|}{ Recipient factors } \\
\hline Pretransplant dialysis duration (months) & 0.011 & $1.012(1.000-1.023)$ \\
\hline
\end{tabular}

respectively, for the groups with and without DGF. A Kaplan-Meier plot of graft survival against DGF occurrence is presented in Fig. 4. According to the log-rank test $(P<0.05)$, 1-year graft survival was impacted by DGF, though no correlation with KDPI based on the log-rank test was found $(P>0.05)$. Due to the limited number of graft losses $(n=6)$, Cox regression was not performed.

\section{Discussion}

DGF is a common complication after kidney transplantation operations and is related to both short-term functional recovery and long-term survival of the transplanted kidney. Yarlagadda et al. [17] systematically reviewed the definitions of DGF, concluding that the combination of Scr reduction and dialysis needs constituted a reasonable definition. However, most centers have recently reached a consensus that the definition of DGF is the need for dialysis within the first week after transplantation [10-12]. As our study adopted the most common definition, DGF cases were relatively few. Consistent with the situation in America, the number of candidates waiting for kidney transplantation is increasing annually in China. Given the strain on kidney resources, the inclusion of ECD has been recognized internationally, even though the utilization of ECD is associated with increased cost and DGF [10]. A systematic review by Tingle et al. confirmed that machine perfusion reduced the incidence of DGF [18]; Patel et al. [19] also demonstrated that HMP can improve the utilization of kidneys. Thus, we used LifePort for marginal kidney perfusion to address such risk as much as possible. Despite the benefits of reducing the resistance parameter after perfusion, perfusion prolonged CIT; we chose $2 \mathrm{~h}$ as the perfusion time based on the research results of Patel et al. [18]. We discarded some bad kidneys according to the parameters of LifePort. Although the included 


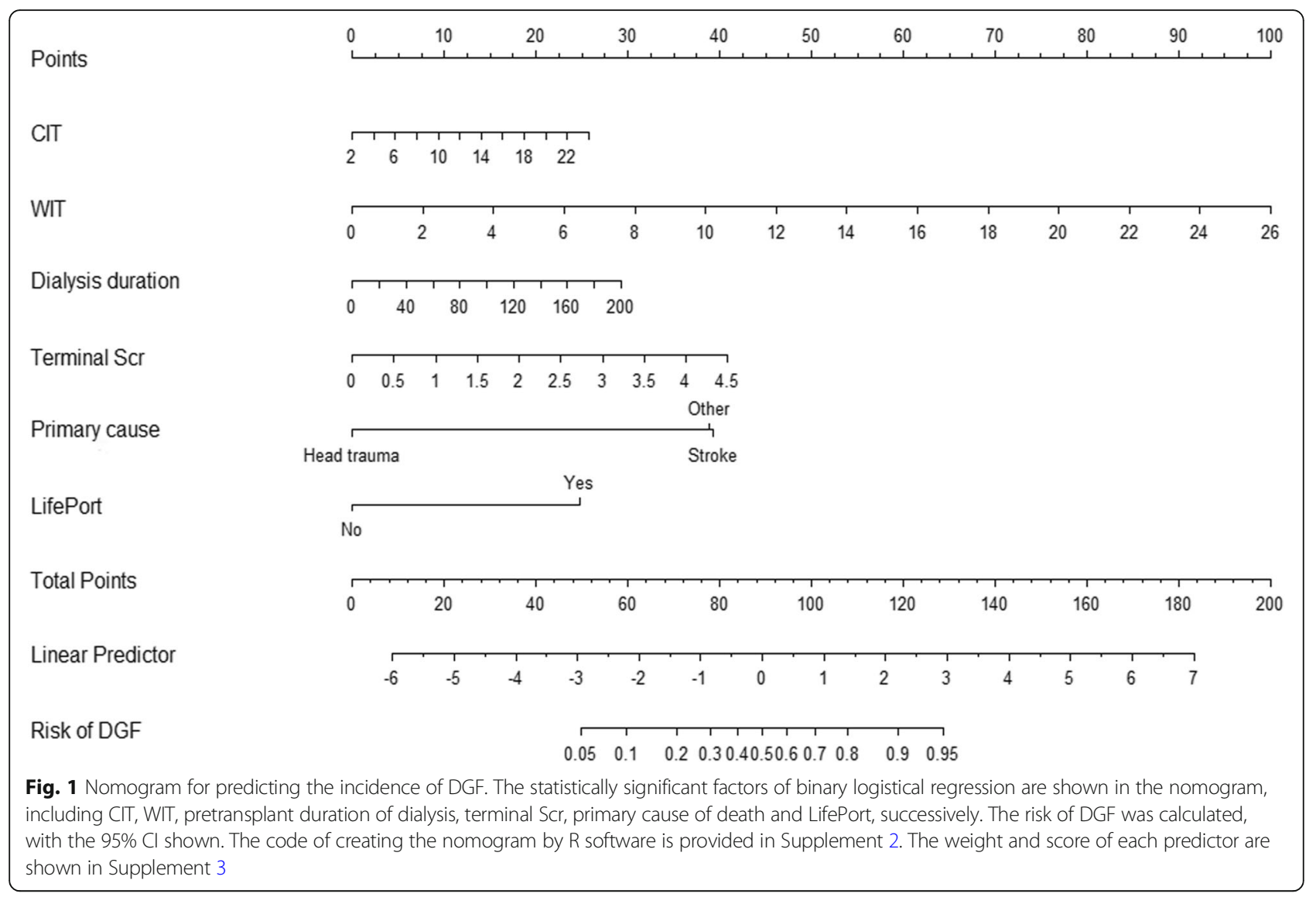

marginal kidneys perfused by LifePort showed statistical correlation with DGF, we still used the kidneys that might have been discarded, accompanied by good 1-year graft survival.

Risk factors related to DGF can be divided into donor factors and recipient factors, and the multiple interactions of these factors ultimately affect the recovery of graft function. Numerous studies have assessed the causes of DGF, yet there is no consensus to date. In our study, prolonged CIT and WIT were most strongly associated with DGF, consistent with previous reports [2027]. Additionally, a longer duration of recipient pretransplant dialysis was likely to lead to DGF. Other donor predictive factors included primary cause of death and terminal Scr. KDPI was introduced in America to indicate the quality of a kidney based on the data from OPTN. Zens et al. [14] also showed that a higher KDPI increased the rate of DGF for kidney recipients, and resulted in shorter graft survival. Nonetheless, other centers have suggested that a high KDPI is not a reason for rejecting a kidney because it does not result in a longterm mortality risk $[15,16]$. In addition, a previous publication showed that the KDPI could not accurately predict pediatric donor kidney survival [28]. In our study, KDPI did not correlate with DGF and 1-year graft survival. The KDPI system does not include WIT and CIT, which may be one of the reasons for the difference. Additionally, the weight of each factor is fixed in the system; when the sample changes and decreases, accuracy also decreases.

Although immunity induction is an important step before surgery to avoid acute rejection, the use of ATG induction remains controversial. ATG may induce cytomegalovirus infections and hematological complications [29, 30]. Popat et al. [31] reported a lower DGF rate in the ATG-induced group among 45 patients in a single-center study. However, ATG induction did not reduce the risk of DGF in the research of de SandesFreitaseta [32]. In our study, the use of ATG depended on the patient's economic condition and the surgeon's preferences because it is costly, and this use was therefore not predictive. The results of our study showed that donor factors were the main influencing factors of DGF, likely because graft quality strongly affects renal function after transplantation. Terminal Scr is the most direct indicator of kidney quality. It is generally believed that the lower is the value, the lower is the incidence of DGF, as observed by Helfer [27] and in the present study.

Although long-term graft survival is expected, numerous complicated factors can cause graft loss. The 


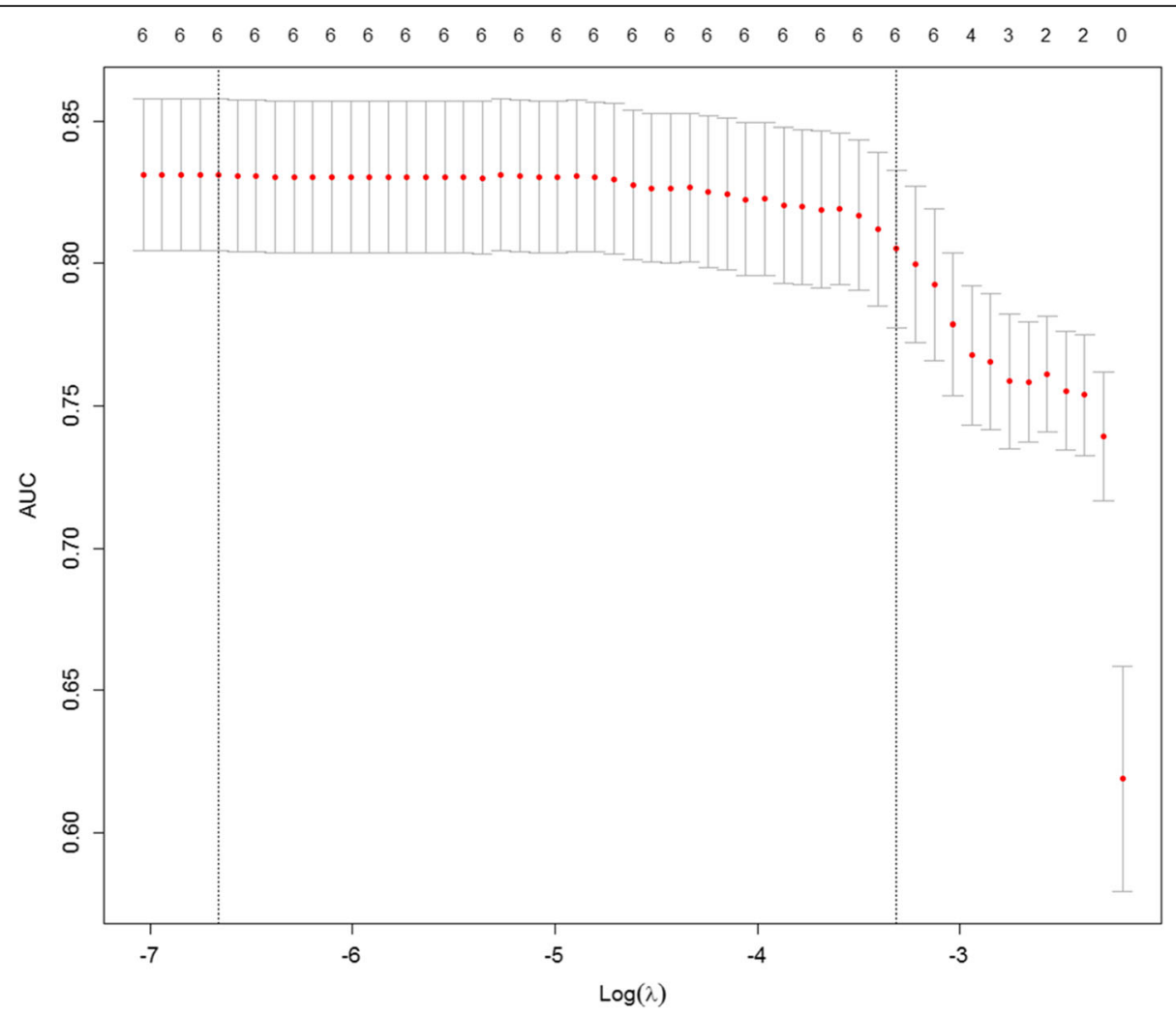

Fig. 2 Internal validation: AUC plot by LASSO. With the log (lambda) value corresponding to the minimum mean-squared error value, the AUC value produced from 10 -fold cross-validation by LASSO was $83.12 \%$

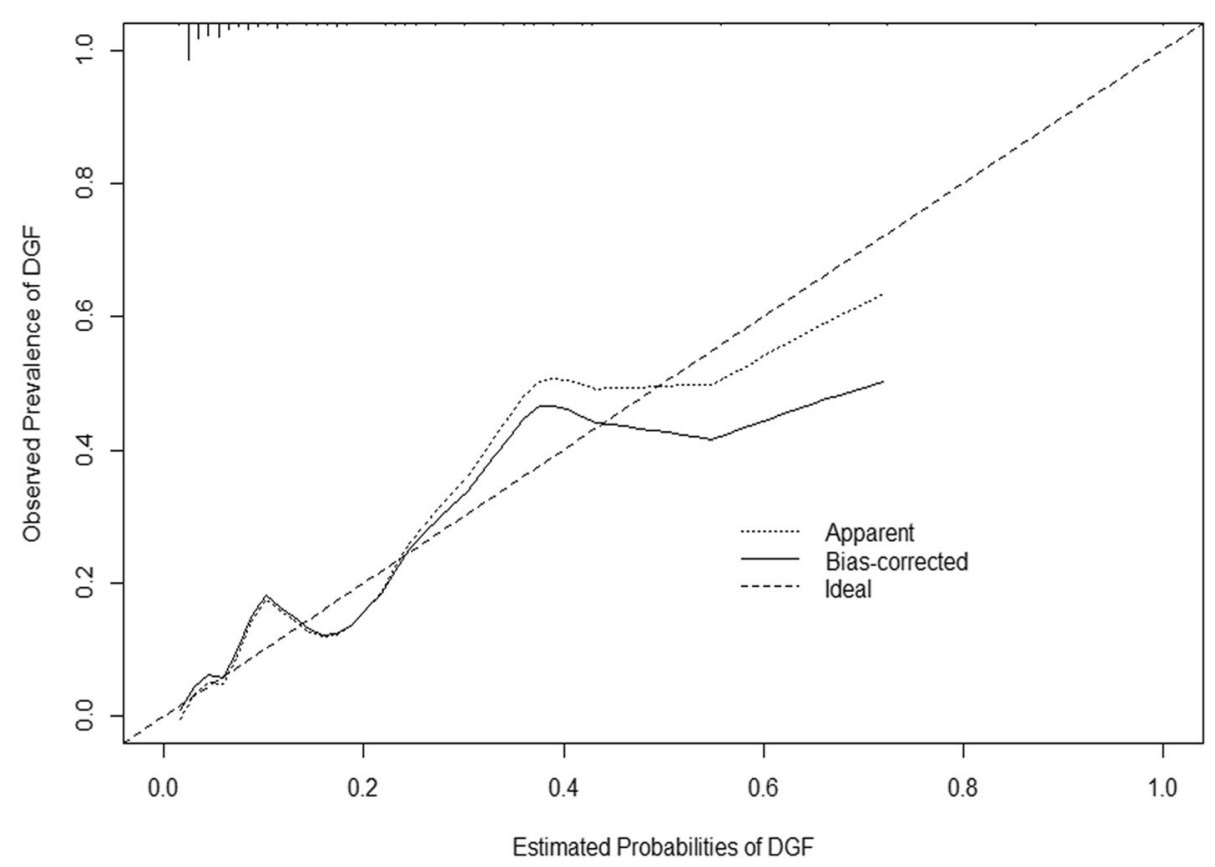

Fig. 3 Calibration plot of the validation cohort. The $x$-axis represents the predicted DGF risk; the $y$-axis represents the actual DGF rate. The diagonal dashed line represents a perfect prediction by an ideal model and the dotted line the performance of the nomogram; the plot shows good agreement between the predicted probabilities and the observed prevalence of DGF 


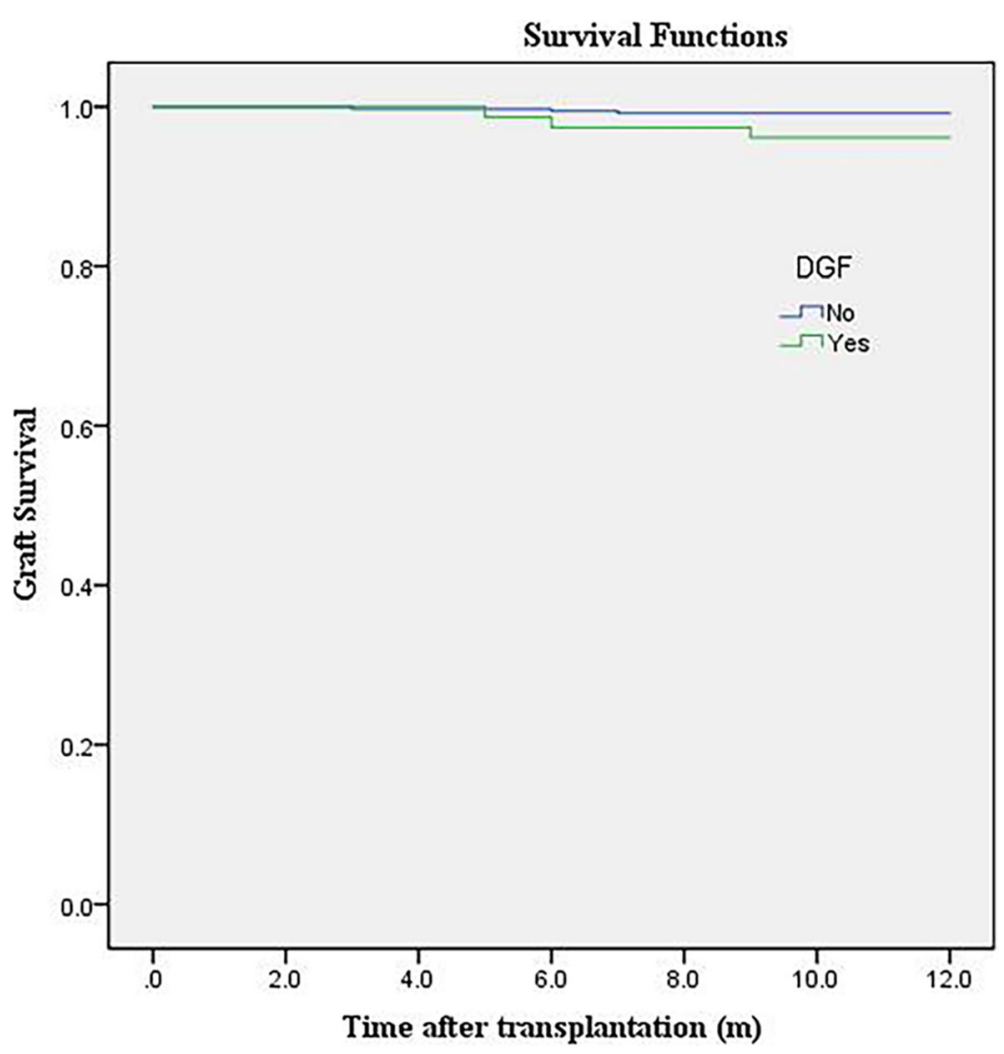

Fig. 4 Kaplan-Meier plot of graft survival for DGF

relationship between DGF and deceased graft survival has been demonstrated recently [33, 34]. In a 3-year DCD kidney registry analysis, Lim et al. [34] reported that the recipients of DCD kidneys with DGF experienced a higher incidence of acute rejection and overall graft loss. Gill et al. [33] observed that the DGFassociated risk of graft failure was greatest in the first posttransplant year, and a meta-analysis by Yarlagadda et al. [35] verified the association between DGF, acute rejection, and graft survival. The present study performed patient follow-up in the training cohort for 1 year, with findings consistent with those reported by Gill et al.

Our nomogram is a simple and visual prediction model of posttransplant factors. Maier et al. investigated the relationship between DGF and posttransplant indicators of neutrophil gelatinase-associated lipocalin (NGAL), reporting that early assessment of serum and urinary NGAL could predict DGF [36]. In their retrospective cohort study, Cardinal et al. [37] used multivariate analysis to examine predictors of DGF but did not distinguish the importance of each. Irish et al. [3, 38] combined numerous donor and recipient factors, and applied nomogram scoring systems for predicting DGF in DD kidney transplantation, which were verified by ROC curves. Previous scoring systems are valuable; on this basis, we incorporated a certain percentage of marginal kidneys, especially young kidneys. Overall, young kidney transplantation was effective and safe, indicating a promising expansion of the donor pool. Infant donors younger than 5 months were excluded from this study, because our center used the novel method of en bloc kidney transplantation introduced by Dai et al. [39]. On the other hand, we investigated new indicators, including KDPI, LifePort and $\mathrm{HCV}$ history. The evaluation and therapeutic effects of LifePort on kidneys are worthy of affirmation, which is consistent with previous findings [40].

The present study applied a 10-fold cross-validation LASSO method to divide the data into 10 equal parts, with nine parts for the model and one part for validation. This process was repeated ten times to produce an accurate AUC.

In addition to identifying patients at higher risk of DGF before surgery, our model may also be used as a clinical tool to reduce the risk of DGF. CIT should be controlled when possible; for example, shortening the harvest and patient preoperative preparation times would reduce CIT, which would help to decrease the incidence of DGF. More specifically, the model can be used as a strategy to select suitable donors and recipients by identifying reasonable matches between recipients' conditions and CIT. Additionally, the model can guide 
immunosuppression induction for high-risk DGF donors identified by the nomogram .

This study had some limitations. First, because this was a single-center study, the sample size was small and data were variable since. Second, the follow-up period of graft function was not long compared to $10-20$ years. Finally, we did not provide solutions for predictors such as WIT. Future studies are needed to explore methods for shortening WIT and to investigate the factors influencing graft survival, as prolongation of graft survival is our ultimate aim.

\section{Conclusion}

This study identified six risk factors as predictors of DGF, including donor CIT, WIT, terminal Scr, primary cause of death, and recipient duration of pretransplant dialysis. A visual nomogram with reliable accuracy was created for clinical use.

\section{Supplementary Information}

The online version contains supplementary material available at https://doi. org/10.1186/s12882-020-02181-1.

Additional file 1: Figure S1. Flow diagram of patient screening

Additional file 2. Supplement 2.

Additional file 3 . Supplement 3.

\section{Abbreviations}

DGF: Delayed graft function; CIT: Cold ischemia time; WIT: Warm ischemia time; BMI: Body mass index; DD: Deceased donation (DD); DBD: Donation after brain death; DCD: Donation after cardiac death; ATN: Acute tubular necrosis; IGF: Immediate graft function; SGF: Slow graft function; ECD: Expanded criteria donor; OPTN: Organ Procurement and Transplantation Network; Scr: Serum creatinine; HPM: Hypothermic machine perfusion; ATG: Antithymocyte globulin; IL-2: Interleukin 2; ICU: Intensive care unit; CPR: Cardiopulmonary resuscitation; HCV: Hepatitis C virus; KDPI: Kidney donor profile index; HLA: Human leukocyte antigen; PRA: Plasma renin activity; AUC: Area under the receiver operating characteristic curve; LASSO: The Least absolute shrinkage and selection operator; SD: Standard deviation; Cl: Confidence interval; NGAL: Neutrophil gelatinase-associated lipocalin

\section{Acknowledgements}

Thanks to the Central South University and China Scholarship Council for funding Rao Chen to study at the University of Pittsburgh.

\section{Authors' contributions}

RC wrote and designed the outline of the manuscript, HW and LS collected data, JH judged DGF, JP calculated KDPI, HD and LP revised the manuscript. The author(s) read and approved the final manuscript.

\section{Funding}

This work was supported by grants from the National Natural Science Foundation of China (81970655, 82070776 and 81800664), Natural Science Foundation of Hunan Province of China (2019JJ50842), and Huxiang Young Talents of Hunan Province (2019RS2013)

\section{Availability of data and materials}

The data used in the study was extracted from our own database, and available from corresponding author on reasonable request.

\section{Ethics approval and consent to participate}

The study was approved by the Ethics Committee of the Second Xiangya Hospital of Central South University. The informed consent was exempted as a retrospective study.

\section{Consent for publication}

Not applicable

\section{Competing interests}

None.

\section{Author details}

${ }^{1}$ Department of Kidney Transplantation, The Second Xiangya Hospital of Central South University, Changsha, Hunan 410011, China. ${ }^{2}$ Clinical Research Center for Organ Transplantation in Hunan Province, Changsha, Hunan 410011, China. ${ }^{3}$ Clinical Immunology Center, Central South University, Changsha, Hunan 410011, China.

Received: 11 August 2020 Accepted: 22 November 2020

Published online: 04 December 2020

\section{References}

1. Gaston RS. Improving long-term outcomes in kidney transplantation: towards a new paradigm of post-transplant care in the United States. Trans Am Clin Climatol Assoc. 2016:127:350-61.

2. Shoskes DA, Cecka JM. Deleterious effects of delayed graft function in cadaveric renal transplant recipients independent of acute rejection. Transplantation. 1998:66(12):1697-701.

3. Irish WD, McCollum DA, Tesi RJ, Owen AB, Brennan DC, Bailly JE, Schnitzler MA. Nomogram for predicting the likelihood of delayed graft function in adult cadaveric renal transplant recipients. J Am Soc Nephrol. 2003;14(11): 2967-74.

4. Geddes CC, Woo YM, Jardine AG. The impact of delayed graft function on the long-term outcome of renal transplantation. J Nephrol. 2002:15(1):17-21.

5. Siedlecki A, Irish W, Brennan DC. Delayed graft function in the kidney transplant. Am J Transplant. 2011:11(11):2279-96.

6. Bahl D, Haddad Z, Datoo A, Qazi YA. Delayed graft function in kidney transplantation. Curr Opin Organ Transplant. 2019;24(1):82-6.

7. Matas AJ, Smith JM, Skeans MA, Thompson B, Gustafson S, Schnitzler MA, Stewart DE, Cherikh WS, Wainright JL, Snyder JJ, Israni A, Kasiske BL. OPTN/ SRTR 2012 Annual Data Report: kidney. Am J Transplant. 2014;14(Suppl 1): $11-44$.

8. Jiang $Y$, Song T, Qiu Y, Liu J, Wang Z, Wang X, Huang Z, Fan Y, Wang L, Lin T. Outcomes of single kidney transplantation from pediatric donors: $A$ single-center experience. Pediatr Transplant. 2018;22(5):e13196.

9. Moudgil A, Dharnidharka VR, Lamb KE, Meier-Kriesche H. Best allograft survival from share-35 kidney donors occurs in middle-aged adults and young children-an analysis of OPTN data. Transplantation. 2013;95(2):319-25.

10. Saidia RF, Eliasa N, Kawaia T, Hertl M, Farrell ML, Goes N, Wong W, Hartono C, Fishman JA, Kotton CN, Tolkoff-Rubin N, Delmonico FL, Cosimi AB, Ko DSC. Outcome of kidney transplantation using expanded criteria donors and donation after cardiac death kidneys: realities and costs. Am J Transplant. 2007;7(12):2769-74

11. Huang J, Wang H, Fan ST, Zhao B, Zhang Z, Hao L, Huo F, Liu Y. The national program for deceased organ donation in China. Transplantation. 2013;96(1):5-9.

12. Wu W, Famure O, Li Y, Kim SJ. Delayed graft function and the risk of acute rejection in the modern era of kidney transplantation. Kidney Int. 2015:88(4): $851-8$.

13. Tai Q, Xue W, Ding $X$, Tian $P$, Xiang $H$, Feng $X$, Yan $H$, Hou J. Perfusion parameters of donation after cardiac death kidneys predict early transplant outcomes based on expanded criteria donor designation. Transplant Proc. 2018:50(1):79-84

14. Zens TJ, Danobeitia JS, Leverson G, Chlebeck PJ, Zitur LJ, Redfield RR, D'Alessandro AM, Odorico S, Kaufman DB, Fernandez LA. The impact of kidney donor profile index on delayed graft function and transplant outcomes: a single-center analysis. Clin Transpl. 2018;32(3):e13190.

15. Massie AB, Luo X, Chow EKH, Alejo JL, Desai NM, Segev DL. Survival benefit of primary deceased donor transplantation with high-KDPI kidneys. Am J Transplant. 2014;14(10):2310-6. 
16. Gandolfini I, Buzio C, Zanelli P, Palmisano A, Cremaschi E, Vaglio A, Piotti G, Melfa $\mathrm{L}$, et al. The kidney donor profile index (KDPI) of marginal donors allocated by standardized pretransplant donor biopsy assessment: distribution and association with graft outcomes. Am J Transplant. 2014; 14(11):2515-25.

17. Yarlagadda SG, Coca SG, Garg AX, Doshi M, Poggio E, Marcus RJ, Parikh CR. Marked variation in the definition and diagnosis of delayed graft function: a systematic review. Nephrol Dial Transplant. 2008;23(9):2995-3003.

18. Tingle SJ, Figueiredo RS, Moir JA, Goodfellow M, Talbot D, Wilson CH. Machine perfusion preservation versus static cold storage for deceased donor kidney transplantation. Cochrane Database Syst Rev. 2019;3(3): CD011671.

19. Patel SK, Pankewycz OG, Nader ND, Zachariah M, Kohli R, Laftavi MR. Prognostic utility of hypothermic machine perfusion in deceased donor renal transplantation. Transplant Proc. 2012:44(7):2207-12.

20. Nieto-Ríos JF, Ochoa-García CL, Serna-Campuzano A, Benavides-Hermosa B, Calderón-Puentes LL, Aristizabal-Alzate A, Ocampo-Kohn C, Zuluaga-Valencia G, Serna-Higuita LM. Time of cold ischemia and delayed graft function in a cohort of renal transplant patients in a reference center. Indian J Nephrol. 2019;29(1):8-14.

21. Jochmans I, Darius T, Kuypers D, Monbaliu D, Goffin E, Mourad M, Ledinh H, Weekers L, Peeters P, Randon C, Bosmans JL, Roeyen G, Abramowicz D, Hoang AD, Pauw LD, Rahmel A, Squifflet JP, Pirenne J. Kidney donation after circulatory death in a country with a high number of brain dead donors: 10-year experience in Belgium. Transpl Int. 2012;25(8):857-66.

22. Kusaka M, Kubota Y, Takahashi H, Sasaki H, Kawai A, Takenaka M, Fukami N, Kenmochi T, Shiroki R, Hoshinaga K. Warm ischemic time as a critical risk factor of graft failure from donors after cardiac death: a single-center experience over three decades in the kidney donor profile index/kidney donor risk index era in Japan. Int J Urol. 2019;26(2):247-52.

23. Puche-Sanz I, Flores-Martín JF, Vázquez-Alonso F, Expósito-Ruiz M, BravoSoto J, Vicent-Prados J, Cózar-Olmo M. Cold ischemia and renal graft survival: a paired analysis comparing first and second grafts from the same donor. Arch Esp Urol. 2016:69(3):121-7.

24. Aceto P, Perilli V, Luca E, Salerno MP, Punzo G, Ceaichisciuc I, Cataldo A, Lai C, Citterio F, Sollazzi L. Perioperative-, recipient-, and donor-related factors affecting delayed graft function in kidney transplantation. Exp Clin Transplant. 2019;17(5):575-9.

25. Ding CG, Tian PX, Ding XM, Xiang HL, Li Y, Tian XH, Li Y, Han F, Tai QH, Han F, Liu QL, Zheng J, Xue WJ. Beneficial effect of moderately increasing hypothermic machine perfusion pressure on donor after cardiac death renal transplantation. Chin Med J. 2018;131(22):2676-82.

26. Helfer MS, Vicari AR, Spuldaro F, Gonçalves LFS, Manfro RC. Incidence, risk factors, and outcomes of delayed graft function in deceased donor kidney transplantation in a Brazilian center. Transplant Proc. 2014;46(6):1727-9.

27. Tugmen C, SERT I, Kebabcı E, Dogan SM, Tanrısev M, Alparslan C, Ayna TK, Olmez M, Karaca C. Delayed graft function in kidney transplantation: risk factors and impact on early graft function. Prog Transplant. 2016;26(2):172-7.

28. Montenovo M, Perkins JD, Kling CE, Sibulesky L, Dick AA, Reyes JD. Machine perfusion decreases delayed graft function in donor grafts with high kidney donor profile index. Exp Clin Transplant. 2020. https://doi.org/10.6002/ect. 2019.0139.

29. Ulrich F, Niedzwiecki S, Pascher A, Kohler S, Kohler S, Weiss S, Fikatas P, Schumacher G, May G, Reinke P, Neuhaus P, Tullius SG, Pratschke J. Longterm outcome of ATG vs. Basiliximab induction. Eur J Clin Investig. 2011: 41(9):971-8.

30. Chen G, Gu J, Qiu J, Wang C, Wang CX, Fei JG, Deng SX, Li J, Huang G, Fu Q, Chen LZ. Efficacy and safety of thymoglobulin and basiliximab in kidney transplant patients at high risk for acute rejection and delayed graft function. Exp Clin Transplant. 2013;11(4):310-4.

31. Popat R, Syed A, Puliatti C, Cacciola R, Cacciola R. Outcome and cost analysis of induction immunosuppression with IL2Mab or ATG in DCD kidney transplants. Transplantation. 2014;97(11):1161-5.

32. De Sandes-Freitas TV, Felipe CR, Aguiar WF, Cristelli MP, Tedesco-Silva H, Medina-Pestana JO. Prolonged delayed graft function is associated with inferior patient and kidney allograft survivals. PLoS One. 2015;10(12): e0144188.

33. Gill J, Dong J, Rose C, Gill JS. The risk of allograft failure and the survival benefit of kidney transplantation are complicated by delayed graft function. Kidney Int. 2016;89(6):1331-6.
34. Lim WH, McDonald SP, Russ GR, JR, Ma MK, Pleass H, Jaques B, Wong G. Association between delayed graft function and graft loss in donation after cardiac death kidney transplants-a paired kidney registry. Transplantation. 2017;101(6):1139-43.

35. Yarlagadda SG, Coca SG, Formica RN Jr, Poggio ED, Parikh CR. Association between delayed graft function and allograft and patient survival: a systematic review and meta-analysis. Nephrol Dial Transplant. 2009;24(3): 1039-47.

36. Maier HT, Ashraf MI, Denecke C, Weiss S, Augustin F, Messner F, Vallant N, Böcklein M, Margreiter C, Göbel G, Pratschke J, Öfner-Velano D, Aigner F. Prediction of delayed graft function and long-term graft survival by serum and urinary neutrophil gelatinase-associated lipocalin during the early postoperative phase after kidney transplantation. PLoS One. 2018;13(1): e0189932.

37. Cardinal H, Lamarche F, Grondin S, Marsolais P, Lagacé AM, Duca A, Albert M, Houde I, Boucher A, Masse M, Baran D, Bouchard J. Organ donor management and delayed graft function in kidney transplant recipients: a multicenter retrospective cohort study. Am J Transplant. 2019;19(1):277-84

38. Irish WD, Ilsley JN, Schnitzler MA, Feng S, Brennan DC. A risk prediction model for delayed graft function in the current era of deceased donor renal transplantation. Am J Transplant. 2010;10(10):2279-86.

39. Dai $H$, Peng L, Peng F, Lan G, Wang $Y$, et al. A novel technique for en bloc kidney transplantation from infant donors with extremely low body weight by using the distal abdominal aorta as an outflow tract. Am J Transplant. 2018;18(9):2200-7.

40. Parker WF, Thistlethwaite JR Jr, Ross LF. Kidney donor profile index does not accurately predict the graft survival of pediatric deceased donor kidneys. Transplantation. 2016;100(11):2471-8.

\section{Publisher's Note}

Springer Nature remains neutral with regard to jurisdictional claims in published maps and institutional affiliations.

Ready to submit your research? Choose BMC and benefit from:

- fast, convenient online submission

- thorough peer review by experienced researchers in your field

- rapid publication on acceptance

- support for research data, including large and complex data types

- gold Open Access which fosters wider collaboration and increased citations

- maximum visibility for your research: over $100 \mathrm{M}$ website views per year

At BMC, research is always in progress.

Learn more biomedcentral.com/submissions 